\title{
A FUNÇÃO SOCIAL DO RÁDIO LOCAL ENTRE DESERTOS DE NOTÍCIA E ZONAS DE SILÊNCIO: reverberaç̧̃̃es da migração AM - FM'
}

\author{
THE SOCIAL ROLE OF LOCAL RADIO BETWEEN DESERTS \\ OF NEWS AND SILENCE ZONES: reverberations of AM - FM \\ migration
}

\author{
Rafael MEDEIROS 2 \\ Universidade Federal de Santa Maria | Brasil
}

\begin{abstract}
Resumo
O processo de migração do rádio AM para FM está transformando a estrutura do sistema de radiodifusão brasileiro e trazendo impactos, sobretudo, para os ouvintes do interior. Um efeito colateral da migração é a diminuição do alcance das emissoras migrantes e até mesmo o fim da cobertura de rádios locais em zonas rurais ou áreas remotas, o que pode aumentar as e zonas de silêncio - cidades sem emissoras de rádio ou televisão - e os desertos de notícia - cidades sem cobertura midiática local. O presente trabalho aborda essa problemática, levando em conta a importante função social das rádios locais e o processo de migração.

\section{Palavras-chave}

Migração; Rádio local; Função social; Zonas de silêncio; Desertos de notícia.

\section{Abstract}

The process of migration from AM to FM radio is transforming the structure of the Brazilian broadcasting system and bringing impacts, especially to the listeners of the interior. One side effect of migration is the reduction in the reach of migrant broadcasters and even the end of coverage of local radios in rural areas, which can increase news deserts - cities without local media coverage - and zones of silence cities without radio or television stations. This paper addresses this problem, taking into account the important social function of local radios and the migration process.

\section{Keywords}

Migration; Local radio; Social role; Silence zones; Deserts of news.
\end{abstract}

\section{RECEBIDO EM 07 DE ABRIL DE 2020}

ACEITO EM 11 DE MAIO DE 2020

\footnotetext{
${ }^{1}$ Versão ampliada e atualizada de trabalho apresentado no III Seminário Internacional de Pesquisas em Midiatização e Processos Sociais. PPGCC-Unisinos. São Leopoldo - RS, maio de 2019.

2 Doutorando do Programa de Pós-Graduação em Comunicação da Universidade Federal de Santa Maria (UFSM). Mestre em Comunicação pela Universidade Federal de Ouro Preto (UFOP). Membro do Grupo de Pesquisa Usos Sociais da Mídia (UFSM) e do Grupo de Pesquisa Convergência e Jornalismo (ConJor UFOP). Contato: rfmedeiros13@gmail.com.
}

João Pessoa - Brasil | ANO 7 VOL.7 N.1 | JAN./JUN. 2020 | p. 360-378 


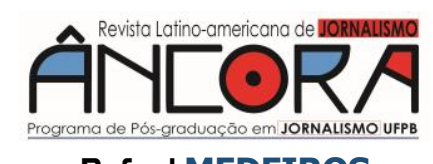

Rafael MEDEIROS

\section{Introdução}

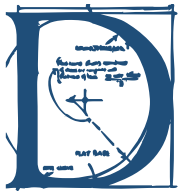

urante sua história o rádio tem passado por diversas mudanças estabelecidas a partir do desenvolvimento tecnológico, de determinações da legislação ou da percepção de novas conformações de seu público. Em referência ao processo constante de mudanças panorâmicas ou estruturais da mídia, Fidler (1997) utiliza o termo midiamorfose para pensar esses fenômenos como a adaptação do sistema de comunicação às mudanças do ecossistema midiático, considerando que novos meios surgem a partir da metamorfose de meios antigos que seguem evoluindo e se adaptando às transmutações.

A partir desse conceito, Prata (2008) desenvolveu o termo radiomorfose para afirmar que o rádio busca essa adaptação e que o meio na internet, embora se configure com características hertzianas, "ao mesmo tempo insere novos formatos, enquanto reconfigura elementos antigos, numa mistura que transforma o veículo numa grande constelação de signos sonoros, textuais e imagéticos" (PRATA, 2008, p. 61). Lopez concorda que "o contexto da radiomorfose afeta práticas, gestão, formas de transmissão, de difusão e de fruição e a própria definição do formato e do conteúdo radiofônicos" (LOPEZ, 2017, p. 1). O rádio é um meio em transformação.

Em 2013 o Governo Federal oficializou o processo de migração de emissoras AM para FM, uma grande metamorfose que tem reconfigurado diferentes esferas da radiodifusão brasileira. O fenômeno tem submetido às rádios migrantes uma nova conformação, alterando suas formas de produção, as possibilidades de veiculação e consumo dos seus conteúdos e até mesmo aspectos da audiência. Como um processo recente e de grande magnitude atingindo mais de $90 \%$ das emissoras AM do país, os desdobramentos e efeitos dessa metamorfose estão sendo conhecidos aos poucos, através de pesquisas que abordam diferentes vieses do fenômeno. 
Um efeito colateral da migração é a diminuição do alcance das emissoras migrantes e até mesmo o fim da cobertura de rádios locais em zonas rurais ou áreas remotas, o que pode aumentar os desertos de notícia - cidades sem cobertura midiática local - e zonas de silêncio - cidades sem emissoras de rádio e televisão. As motivações apresentadas para a consolidação da ida das emissoras AM para FM são relevantes, mas não se pode desconsiderar a importância das emissoras em Amplitude Modulada para muitas comunidades que, após o desligamento do sinal AM, ficarão sem cobertura de rádio local.

O artigo se desdobra de uma pesquisa de recepção ${ }^{3}$ realizada em 2018 com ouvintes da Rádio Itatiaia Ouro Preto, uma emissora local da cidade mineira de Ouro Preto ${ }^{4}$, e teve o objetivo de identificar possíveis mudanças nas experiências de escuta e produção de sentidos a partir do processo de migração da emissora para FM (MEDEIROS, 2019). Com base multimetodológica que combinou aplicação de questionários, entrevistas com ouvintes e com gestores da rádio e análise textual discursiva, o estudo verificou a estruturação do local social da escuta radiofônica, pensando que os ouvintes estão inseridos em núcleos variegados e tangentes sociais que moldam efetivamente suas memórias e percepções da realidade cotidiana. $O$ artigo ora desenvolvido busca flexionar questões referentes à função social do rádio local para as comunidades interioranas e algumas inseguranças trazidas pelo processo de migração, que pode amplificar as chamadas zonas de silêncio no Brasil.

\section{O processo de migração do rádio AM para FM no Brasil}

As mudanças na estrutura das emissoras AM representam um pedido antigo dos radiodifusores baseado na queda de rendimento dessas rádios após

\footnotetext{
${ }^{3}$ A pesquisa foi realizada sob orientação da Profa Dra Nair Prata no âmbito do Programa de Pós-Graduação em Comunicação da Universidade Federal de Ouro Preto (UFOP), justificando também a escolha da emissora investigada.

${ }^{4}$ Ouro Preto se localiza na região central do estado de Minas Gerais, a $96 \mathrm{~km}$ da capital. A população estimada da cidade em 2018 era de 74 mil habitantes (IBGE, 2018).
}

João Pessoa - Brasil | ANO 7 VOL.7 N.1 | JAN./JUN. 2020 | p. 360-378 


\section{ANILORA}

Rafael MEDEIROS

longo período de desvalorização pela falta de interesse do Governo, pelas mudanças tecnológicas que beneficiaram apenas a Frequência Modulada e pela concorrência por anunciantes que foi ampliada pelas redes digitais e pela introdução de novos dispositivos. Os investimentos no sistema de TV digital fizeram acirrar ainda mais essas reivindicações dos donos de rádio ao passo em que essa digitalização das emissoras de TV representou uma possibilidade para a mudança preterida no sistema brasileiro de radiodifusão sonora.

Os principais motivos apontados pelo então Ministério das Comunicações para a migração são ligados à melhora da qualidade do som, menor interferência no sinal e a possibilidade da sintonia através de dispositivos móveis como smartphones - que suportam apenas a faixa FM. Além disso, fatores econômicos também podem ser apontados como motivação para o início desse processo, uma vez que as emissoras AM vinham sofrendo com a queda de audiência e anunciantes (FARIAS; ZUCULOTO, 2017, p. 9) e os canais liberados por essas rádios poderão ser usados por empresas de telefonia. É preciso deixar claro que a maioria dos dados disponíveis sobre variações de audiência ${ }^{5}$ no rádio são de pesquisas realizadas em regiões metropolitanas, o que pode não representar a realidade dos interiores do Brasil. Desse modo, o próprio governo usa dados gerais para justificar as motivações do início do processo de migração e desconsidera as diversas particularidades das rádios e audiências locais.

Após estudos realizados desde 2010, o processo foi oficializado pela então presidenta Dilma Rousseff no dia 07 de novembro de 2013 através do Decreto 8.139 (BRASIL, 2013). Durante a cerimônia de oficialização do início da migração, o então presidente da Associação Brasileira de Emissoras de Rádio e Televisão (ABERT) destacou que "a assinatura do decreto é o fato mais relevante para o rádio AM nos últimos 50 anos" (SLAVIERO apud

\footnotetext{
${ }^{5}$ Pesquisas da Kantar Ibope Mídia que monitoram os índices de audiência do rádio nas regiões metropolitanas brasileiras apontam que, entre setembro e novembro de $2016,8,3 \%$ dos ouvintes de rádio em Belo Horizonte estavam sintonizados em emissoras AM, já entre novembro de 2017 e janeiro de 2018 esse número caiu para 6,9\% (KANTAR IBOPE MEDIA, 2018a; 2018b).
} 
MACEDO, 2013, s.p). A estagnação da radiodifusão brasileira, sobretudo das emissoras AM, é de fato notória também porque se trata de um sistema baseado em uma legislação antiga, ultrapassada e que desconsidera diversos desenvolvimentos tecnológicos já assimilados por uma parcela considerável de ouvintes e até mesmo por muitas empresas de comunicação como, por exemplo, o consumo de rádio em mobilidade.

Como exemplificação desse comportamento de consumo radiofônico, Del Bianco e Prata (2018) esclarecem que "o celular se converteu na principal porta de entrada para o consumo de rádio, além de alargar as formas de mobilidade antes restritas aos aparelhos transistorizados e de automóvel" (DEL BIANCO; PRATA, 2018, p. 99). Ao disponibilizar no mercado apenas aparelhos celulares e sons automotivos que são compatíveis exclusivamente com a sintonia do rádio em FM, a indústria acelerou o enfraquecimento das emissoras AM e contribuiu, dessa maneira, para a aceitabilidade do processo de migração. Embora muitas emissoras AM - mesmo as locais - transmitam também via streaming pela internet, é necessário levar em conta, mais uma vez, a qualidade da conexão e o alcance ainda limitado dos serviços. 0 consumo de rádio em mobilidade permitiu ainda aumentar os potenciais interativos do meio, complexificar narrativas usando espaços agora multimidiáticos. Dessa forma, consumir rádio em mobilidade não se trata apenas da possibilidade de escuta pelo celular, mas representa uma mudança na estrutura da radiodifusão sonora, nas experiências de escuta e modos de consumo do áudio - transformações que não incluíam as tradicionais emissoras AM.

Nesse cenário, das 1.781 emissoras comerciais que operavam em AM no Brasil, 1.720 solicitaram a mudança de frequência e 786 delas já estão operando na faixa de $\mathrm{FM}^{6}$. A primeira emissora a concluir o processo de

\footnotetext{
${ }^{6}$ Dados da Associação Brasileira de Emissoras de Rádio e Televisão (ABERT) atualizados no mês de fevereiro de 2020.
}

João Pessoa - Brasil | ANO 7 VOL.7 N.1 | JAN./JUN. 2020 | p. 360-378 


\section{ANILORA}

Rafael MEDEIROS

migração foi a Rádio Progresso, de Juazeiro do Norte, no Ceará, que passou a operar em FM no dia 18 de março de 2016 . Com mais de $75 \%$ das emissoras solicitantes já autorizadas a operar em Frequência Modulada, o Governo Federal fixou para 2022 a data de conclusão de todas as atividades de migração. Segundo o MCTIC, as rádios AM nacionais e regionais que se recusaram a aderir ao processo de migração continuam operando normalmente, mas existem pesquisas ${ }^{7}$ que afirmam que o atual modelo do AM não se sustentará por muitos anos e que as emissoras AM não migrantes na prática deixarão de existir ou estarão ainda mais isoladas no universo da radiodifusão nacional ${ }^{8}$.

Uma preocupação que se tem quanto ao processo de migração é a redução da área de cobertura das emissoras depois da ida para a faixa de FM. O estudo inicial da ABERT (2010) sobre a viabilidade da migração considera acertadamente que as emissoras brasileiras em AM atualmente não têm mais caráter expansivo, elas não mais transbordam para outros estados e menos ainda para outros países, pelo contrário, elas se voltam para suas localidades tanto em cobertura quanto na formatação de suas programações. Existem pesquisas (AVRELLA, 2014; ZUCULOTO et. al., 2018; LOPEZ et. al., 2018) que nesse mesmo sentido apontam emissoras migrantes que ganharam alcance após a ida para o FM. Essa amostra é importante como dado, porém se baseia em alguns casos específicos e em emissoras AM de baixa potência, desconsiderando rádios que abrangem áreas remotas, municípios de grande extensão territorial ou com vasta área rural, por exemplo.

É um equívoco a avaliação de que as AMs locais não migrantes, que estão se transformando em regionais, terão capacidade de atingir grandes áreas, já que o contorno máximo protegido dessas rádios não ultrapassará 30

\footnotetext{
7 CURADO, 2015; JOBIM, 2015; FARIAS e ZUCULOTO, 2017.

8 Grandes redes, como o Sistema Globo de Rádio, já estão eliminando parcerias com afiliadas que permaneceram operando em AM. Conforme Massaro (2018, s.p.), "o Sistema Globo de Rádio já não afilia mais emissoras na faixa AM há pelo menos dois anos, mantendo apenas as afiliadas AMs que já estão em processo de migração para a faixa FM. Toda a expansão recente envolveu rádios FMs".
} 
quilômetros desconsiderando especificidades geográficas e topográficas. É preciso, portanto, relativizar esses dados que indicam baixa expansividade das emissoras em AM e um possível aumento da área de alcance após a migração quando se pensa em um país de tamanho continental como o Brasil, com múltiplas representações sociais e geográficas. Muitas localidades no país não têm sequer acesso a sinal de televisão ou de telefone, para as populações desses lugares o único meio de informação é o rádio AM. A diminuição do alcance de muitas emissoras de rádio após a migração chega a ser tão drástico que vai deixar populações de áreas remotas e comunidades afastadas da sede do município sem informação local, acendendo o alerta para um possível aumento de zonas de silêncio.

O efeito colateral é que a mudança ondulatória da amplitude modulada (AM) para a frequência modulada (FM) vai diminuir drasticamente o alcance, abandonando justamente o público mais dependente desse modelo: as populações das pequenas cidades, campo, sertões e florestas. Ou seja, mais convergência e menos abrangência (BERTOLOTTO, 2018, s.p).

Para além dos fatores técnicos do processo de migração, pensando na função social que as emissoras AM desempenham e considerando o fenômeno como um todo, em sua importância e magnitude, a pesquisadora Daniela Ota, citada por Bertolotto (2018), destaca que "nas rádios pantaneiras ainda tem o tradicional programa de recados. Pessoas avisando que vão chegar de viagem, quem morreu, quem nasceu. $\mathrm{O}$ rádio é essencial ali, e a mudança para a FM vai prejudicar essa população" (OTA apud BERTOLOTTO, 2018, s.p).

Nesse sentido, a migração pode potencializar dois fenômenos preocupantes no cenário comunicacional e social brasileiro: os desertos de notícias e as zonas de silêncio. $O$ próximo tópico problematiza alguns possíveis efeitos da migração para o rádio local apresentando também a dimensão atual dos desertos de notícias e zonas de silêncio. 


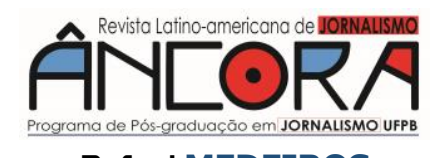

Rafael MEDEIROS

\section{Identidade local e função social do rádio}

No contexto de desenvolvimento do processo de migração, algumas das características do rádio na relação com a audiência deverão ser alteradas. Tomando como base o município de Ouro Preto, onde a pesquisa empírica foi realizada, todos os doze distritos ouro-pretanos ficarão sem a cobertura da Rádio Itatiaia Ouro Preto após o desligamento do sinal AM. Isso representa um impacto no que diz respeito à identidade local, já que a mídia ajuda a conformar ou modificar modos identitários, uma vez que "o consumo cultural midiático participa da organização da cotidianidade e da conformação da competência cultural" (RONSINI, 2007, p. 70). A abordagem do conceito de identidade local não é reiterada de maneira despretensiosa neste texto, mas assume atribuição importante na convergência dialógica entre emissora e ouvinte, na produção e manutenção de discursos e sentidos sobre um espaço comum.

O conceito de identidade tem sido fundamental para pesquisas de diferentes áreas do conhecimento e ganhou relevância na busca por respostas em investigações que tratam de diversas mobilizações da vida social, incluindo as relações entre território e os modos de vida. Ao passo em que se ampliam os estudos, o conceito segue ganhando variegadas interpretações. Autores como Bourdieu (2003) e Giddens (2002) olham para a identidade sob uma perspectiva das características individuais do sujeito, como "representação de si" ou como forma de distinção dentro de um cerne social. Já Hall (2006), Bauman (2005) e Canclini (2005), entre outros, percebem a questão da identidade sob o eixo da cultura, considerando os sentimentos de pertença, a formação cultural gerada na comunicação simbólica entre seres humanos. Desse modo, "as identidades culturais são pontos de identificação, os pontos instáveis de identificação ou sutura, feitos no interior dos discursos da cultura e da história" (HALL, 1996, p. 70). É nesse segundo sentido que a ideia de identidade local é apropriada no presente artigo, uma vez que a definição de local é atravessada pela questão da identidade, considerando que o local diz 
de "um espaço restrito, bem delimitado, no interior do qual se desenrola a vida de um grupo ou de um conjunto de pessoas. Ele possui um contorno preciso, a ponto de se tornar baliza territorial para os hábitos cotidianos" (ORTIZ, 1999, p. 54).

Assim, "o local coloca em forma o mundo da vida diária, sendo ele próprio fundador da relação com o mundo do indivíduo, mas igualmente da relação com o outro, da construção comum do sentido que faz o vínculo social" (BOURDIN, 2001, p. 36). A comunicação aparece nessas interlocuções entre a cotidianidade, manutenção de identidade e possibilidade de representação no sentido que lhe dá Martín-Barbero:

A comunicação é percebida, em todo caso, como o cenário cotidiano do reconhecimento social, da constituição e expressão dos imaginários a partir dos quais as pessoas representam aquilo que temem ou que têm direito de esperar, seus medos e suas esperanças (MARTÍN-BARBERO, 2003, p. 63).

Para a população local, os meios de comunicação, em especial o rádio, assumem papel importante na constituição das subjetividades, dialogismos e relações sociais. Como evidencia Kischinhevsky, "o rádio é o meio de comunicação eletrônica mais local jamais desenvolvido, mesmo tendo hoje alcance planetário" (KISCHINHEVSKY, 2016, p. 134) ${ }^{9}$. Além do mais, a função social do rádio e sua posição relevante em diversos aspectos da vida diária das pequenas cidades costuram-se às percepções assinaladas acima por MartínBerbero. O rádio local anuncia objetos perdidos, veicula notas falecimentos, convites para missas e até mesmo serve de elo de comunicação entre pessoas da sede do município e habitantes da zona rural através de recados individuais que um cidadão destina a outro (RADDATZ, 2011). Também nessa perspectiva, uma função social importante da comunicação local é destacar

\footnotetext{
${ }^{9}$ Para o autor, a forma de relação estabelecida entre a audiência e o meio faz com que o rádio tenha que "escutar permanentemente seus públicos". Esses públicos têm a possibilidade de apontar para a emissora o que querem ouvir, podem contribuir com informações, reverberar notícias e interagir de maneira mais próxima com os comunicadores, "forçando o rádio a ser melhor, a prestar serviços de utilidade pública, a informar correta e eticamente, a apresentar a diversidade social e cultural, sem representar clichês e estereótipos" (KISCHINHEVSKY, 2016, p. 134).
}

João Pessoa - Brasil | ANO 7 VOL.7 N.1 | JAN./JUN. 2020 | p. 360-378 


\section{ANTEORA}

Rafael MEDEIROS

assuntos que não têm espaço na grande mídia, favorecendo a mobilização social em torno de problemas que afetam diretamente a vida das pessoas e muitas vezes são negligenciados por governantes. Peruzzo (2005) conclui que, na mídia local, "o protagonismo principal está nos cidadãos, que, através de organizações da sociedade civil sem fins lucrativos, instituem processos de comunicação com vistas à mobilização social e à ampliação da cidadania" (PERUZZO, 2005, p. 43). Assim, o rádio local é colocado como mediador entre as demandas da população e as instâncias governamentais.

As emissoras locais têm capacidade de reforçar laços e identidades socioculturais porque a rádio "está centrada na vida social, econômica, política e cultural de sua área de abrangência e também em tudo o que ocorre em seu exterior e que tenha repercussões na vida da comunidade" (CEBRIÁN HERREROS, 2001, p. 98, tradução nossa ${ }^{10}$ ). Nesse sentido, Soares, citada por Bertolotto (2018), expõe que "a AM entra pelos igarapés até as comunidades ribeirinhas. Nas casas de farinha, o som é do radinho. Ele fortalece nossa identidade e traz conhecimento. Na Amazônia, ela é tão primordial como o WhatsApp para as pessoas da cidade" (SOARES apud BERTOLOTTO, 2018, s.p).

Uma das importantes funções sociais da comunicação é prestar serviços de utilidade pública, informando sobre acontecimentos que afetam diretamente a vida das pessoas. Os desdobramentos da migração nas emissoras de pequeno porte têm impacto direto nesse caráter do rádio local. A Rádio Itatiaia Ouro Preto, tomada como empiria neste artigo, é o principal meio de comunicação usado pela prefeitura da cidade patrimônio para levar à população informações sobre campanhas de vacinação, coleta de lixo, atendimento médico e outras de caráter extremamente relevante para a comunidade, especialmente para as áreas rurais. Por mais que não fique desamparada de notícias nacionais e regionais, a população desses lugares

\footnotetext{
${ }^{10}$ No original: Se centra en la vida social, económica, política y cultural de cada lugar o bien en todo cuanto se genera en el exterior con repercusiones en la vida de la localidad.
} 
perderá uma fonte de informações relevantes que dizem respeito às suas atividades diárias.

\section{O rádio local entre desertos de notícia e zonas de silêncio}

As desigualdades sociais brasileiras também podem ser verificadas pelo acesso aos meios de comunicação nas diferentes regiões e em uma comparação entre distintas realidades. A internet, por exemplo, chega a $75 \%$ dos domicílios urbanos e em apenas 41\% dos domicílios rurais (IBGE, 2018). Essa realidade desigual de acesso à informação é verificada também pela existência de desertos de notícias no Brasil, isto é, municípios que não contam com sequer um meio jornalístico local. Pelos motivos expressos nos parágrafos anteriores, a migração aumenta as desigualdades de acesso à informação no país continente.

Pesquisa divulgada em fevereiro de 2020 pelo Instituto para o Desenvolvimento do Jornalismo (ProJor) ${ }^{11}$, mantenedor do Observatório da Imprensa, mapeou cerca de catorze mil veículos de comunicação e constatou que $18 \%$ da população nacional, em $62 \%$ dos municípios, vive em desertos de notícia - municípios sem a presença registrada de veículos jornalísticos locais, como jornais, sites noticiosos, emissoras de TV e rádios. Além disso, quase $20 \%$ dos municípios brasileiros são considerados quase desertos, contando com apenas um ou dois canais noticiosos, assim, 64 milhões e 800 mil pessoas vivem em desertos ou quase desertos de notícias. No mapa a seguir (Figura 1), os 3.487 municípios considerados pela pesquisa como desertos de notícia estão destacados em vermelho.

\footnotetext{
${ }^{11}$ Chamada de Atlas da Notícia, a pesquisa tem o objetivo de mapear veículos produtores de notícias no Brasil, com olhar prioritário para o jornalismo local. A metodologia se baseia na contabilização e localização de veículos de notícia no Brasil, através de levantamento próprio e de outros institutos, incluindo o IBGE e MCTIC. A pesquisa conta com o apoio da Sociedade Brasileira de Estudos Interdisciplinares da Comunicação (Intercom).
}

João Pessoa - Brasil | ANO 7 VOL.7 N.1 | JAN./JUN. 2020 | p. 360-378 


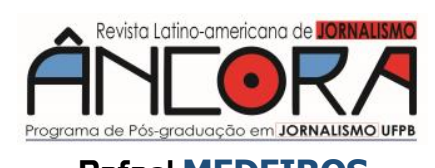

Rafael MEDEIROS

Figura 1 - O mapa dos desertos de notícia no Brasil

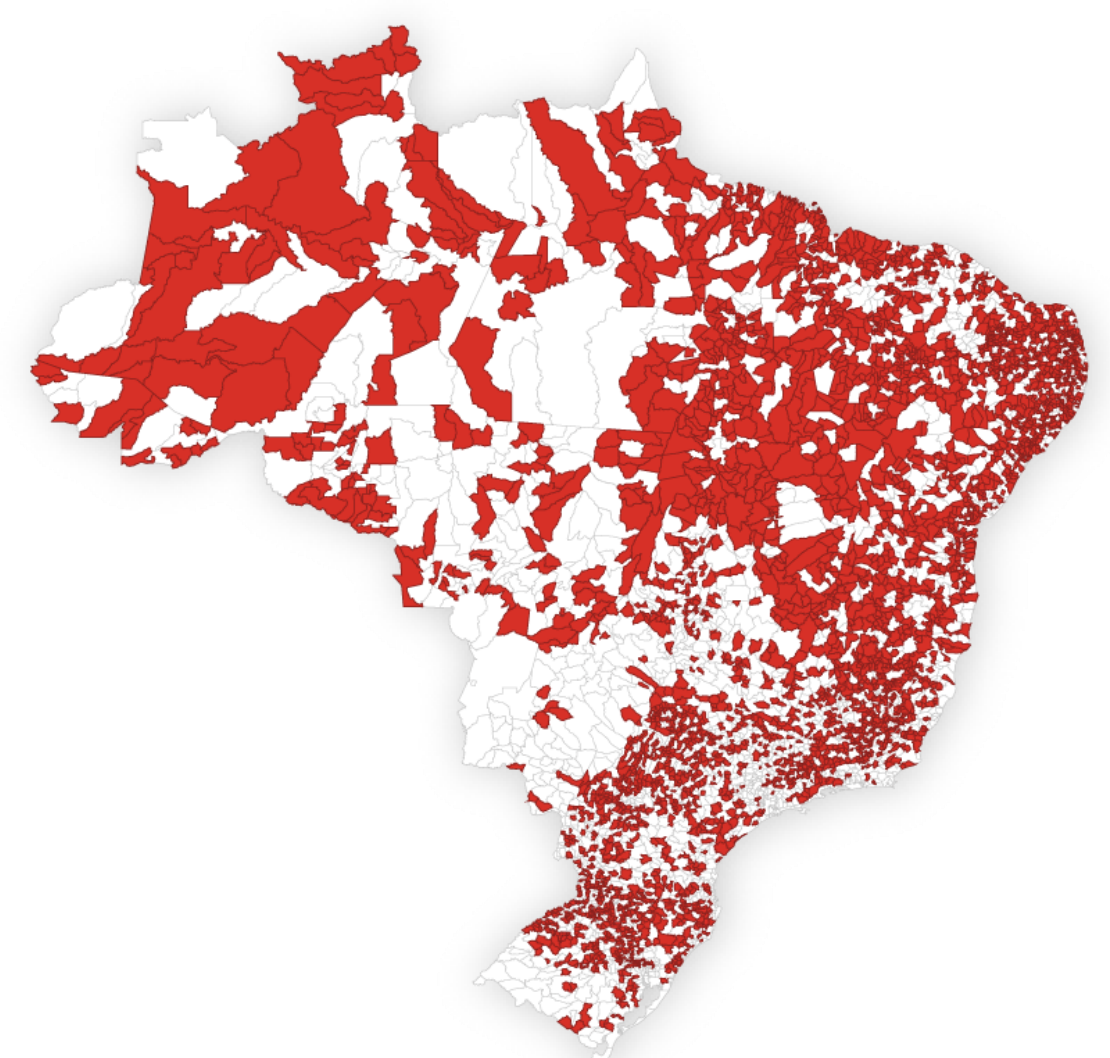

Fonte: Instituto para o Desenvolvimento do Jornalismo (2020).

Dados da pesquisa do ProJor apontam ainda que os municípios do Norte e Nordeste têm o pior cenário em relação à cobertura regional: 73,5\% das cidades do nordeste e $71,8 \%$ dos municípios do norte do país podem ser considerados desertos de notícias, enquanto no Sudeste o índice cai para $60,6 \%$ e para $54,8 \%$ no Sul (PROJOR, 2020). A pesquisa também aponta a correlação entre o Índice de Desenvolvimento Humano e a presença de imprensa ao verificar que cidades que não são desertos de notícia têm IDH maior, o que alerta ainda mais para a importância dos meios locais, sobretudo do rádio, em áreas remotas e de baixo desenvolvimento, muitas vezes com sistemas de comunicação precários.

Essa relevância fica explícita em pesquisa do Instituto Ipsos realizada em 2018 que elencou o Brasil como o quinto país que tem a população com a percepção mais equivocada da própria realidade (IPSOS, 2018). Considerando 
que a mídia afeta diretamente a percepção das pessoas sobre a realidade, os desertos de notícias podem ser vistos como importantes agentes na desinformação da população. Para Hack e Rosa (2019, s.p.), "não há como reconhecer uma realidade sobre a qual não se tem acesso. E não estamos falando de uma realidade em nível nacional apenas, mas de uma realidade local, com a qual os cidadãos têm contato e que influencia diretamente em suas ações". Correlato a isso, os desertos de notícias deixam ainda espaço para fontes de informação não confiáveis e para a propagação de fake news que afetam diretamente a vida das pessoas, sobretudo as que vivem em áreas com menos desenvolvimento social.

Além dos desertos de notícias, o Atlas da Notícia mapeou, em 2018 ${ }^{12}$, as zonas de silêncio, que são cidades sem nenhuma emissora de rádio ou televisão. Considerando que, desde a sua popularização, o rádio sempre foi o meio de comunicação mais abrangente em todo o país, tendo a possibilidade de chegar a comunidades onde nenhuma outra modalidade midiática consegue acessar, as zonas de silêncio são menores que os desertos de notícia, mas mesmo assim os dados divulgados pela pesquisa com foco em radiodifusão mostram que $25 \%$ dos brasileiros não têm acesso a emissoras locais de rádio e televisão.

No mapa seguinte (Figura 2), os espaços em branco representam os municípios considerados zonas de silêncio no Brasil.

12 Não foram divulgados dados específicos da radiodifusão na pesquisa mais atual da ProJor. A despeito disso, os dados inseridos aqui são relevantes para o entendimento do contexto das zonas de silêncio. Ademais, como não são feitas comparações, não há perda na interpretação dessas informações no presente artigo.

João Pessoa - Brasil | ANO 7 VOL.7 N.1 | JAN./JUN. 2020 | p. 360-378 


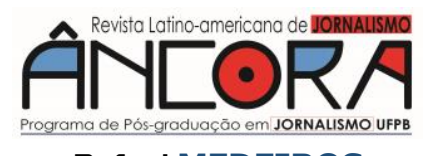

Rafael MEDEIROS

Figura 2 - Zonas de silêncio no Brasil

\section{Mapa da radiodifusão*}

REGIÖES

Centro-Oeste

- Nordeste

Norte

- Sudeste

Sul

$\square$ sem emissoras mapeadas

${ }^{*}$ Cidades com uma ou mais

emissoras de rádio ou TV

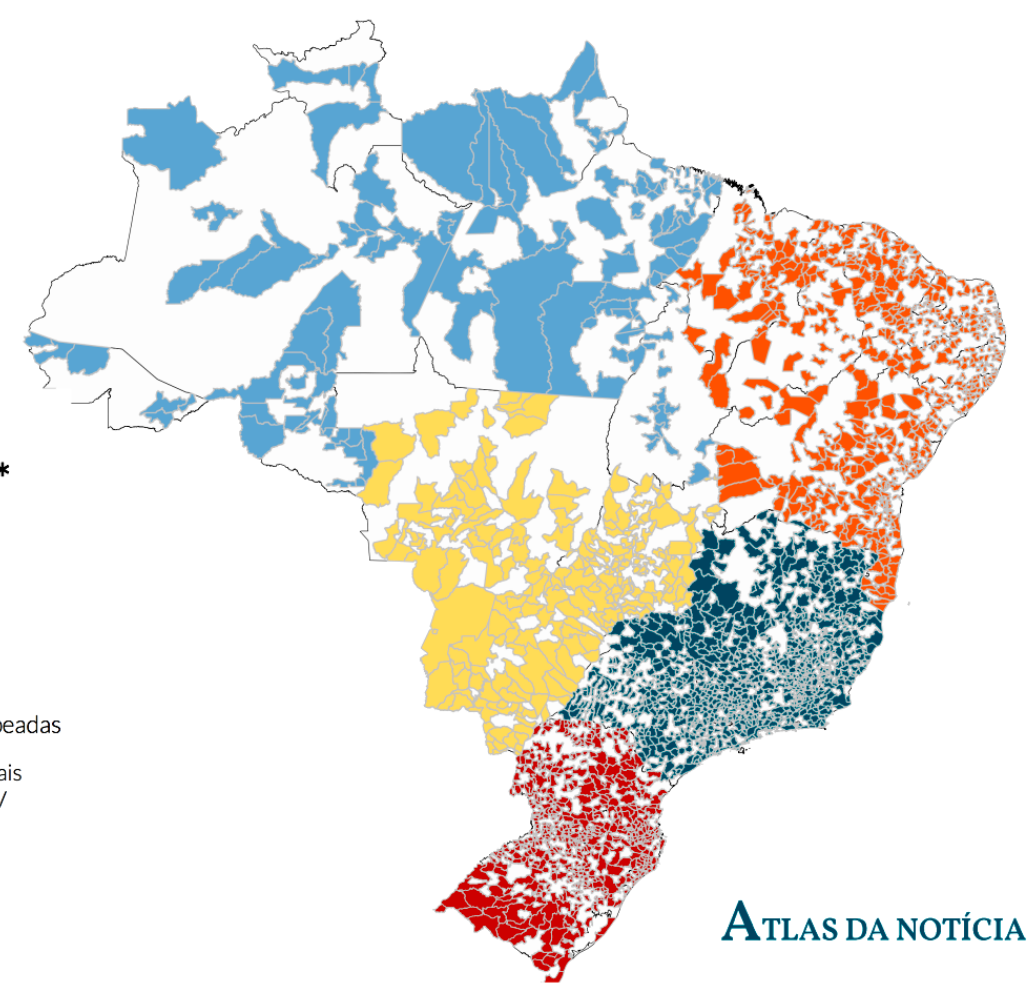

Fonte: Instituto para o Desenvolvimento do Jornalismo (2018).

O rádio ainda é importante e insubstituível quando se considera a imediaticidade do meio e as divisões geopolíticas das localidades, já que informações e avisos cotidianos referentes ao município onde esses lugares estão vinculados são veiculados pelos meios de comunicação locais. As dificuldades de acesso à tecnologia ainda são barreiras para a disseminação de meios de comunicação online em cidades pequenas e algumas regiões do Brasil. O gráfico a seguir mostra que o rádio segue tendo importância expressiva entre os meios de comunicação no Brasil por sua abrangência e facilidade de acesso. 
Gráfico 1 - Mídias mapeadas pelo Atlas da Notícia em 2019

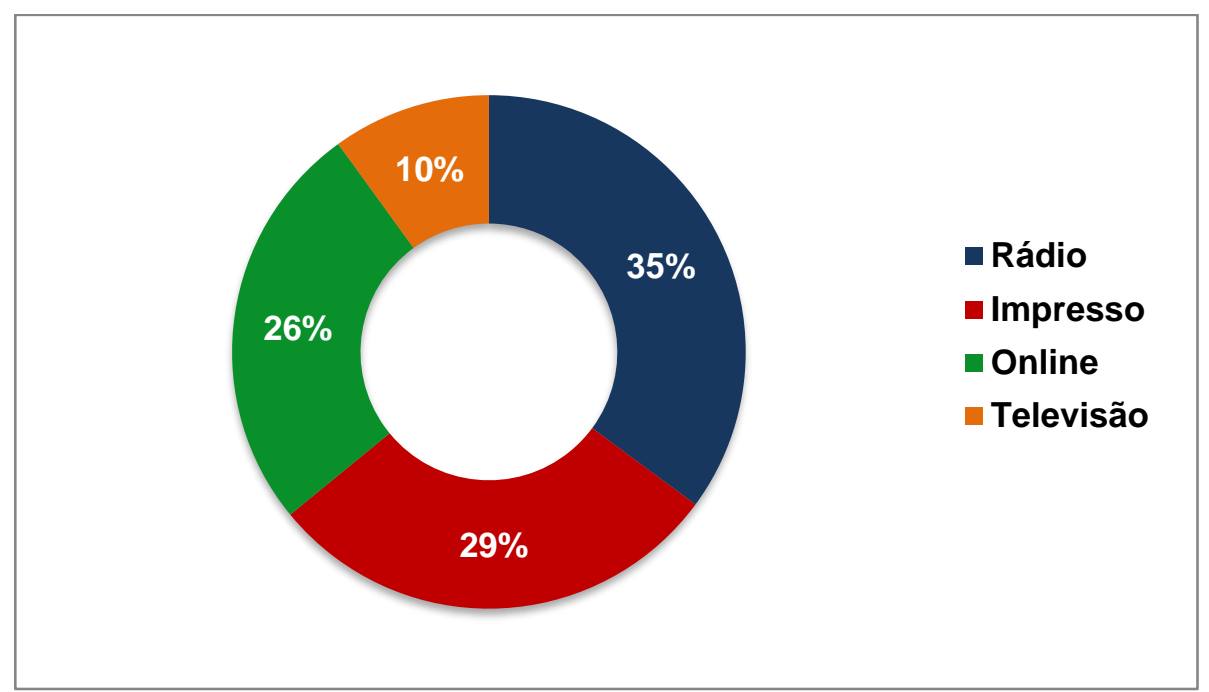

Fonte: Adaptado de Instituto para Desenvolvimento do Jornalismo (2020).

A pesquisa mostra ainda que a população de regiões mais afastadas dos grandes centros é dependente do rádio e que cidades menores tendem a ter cobertura menos satisfatória. Cidades consideradas desertos de notícias têm em média 11 mil habitantes, já as que não são desertos têm população média de 65 mil pessoas. Outro dado que confirma essa dependência é a não correlação entre a taxa de rádio e televisão por habitante e o IDH, ou seja, o rádio continua chegando a lugares em que outros veículos não vão e, assim, continua sendo o meio mais democrático do país.

\section{Considerações finais}

Os desertos de notícias privam a população de ter informações sobre a própria realidade, além de impactar nas relações sociais entre moradores e na manutenção de identidades culturais locais, representando uma ameaça à democracia em meio à crise de credibilidade midiática que vem sendo amplificada pela emergência das fake news. As informações que chegam até as pessoas que vivem em desertos de notícias falam de uma realidade que para elas é plastificada ou não interessa aos seus cotidianos, em detrimento de informações sobre serviços básicos que afetam diretamente suas vidas. 


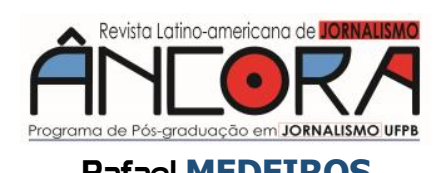

As zonas de silêncio também representam um problema para localidades distantes dos centros urbanos, já que em muitas dessas regiões o rádio se configura como única forma de acesso a informações sobre serviços como coleta de lixo e abastecimento de água. É o rádio que muitas vezes faz o papel de relógio e de portador de recados entre moradores, noticia objetos perdidos e compartilha com os sinos das igrejas os avisos de falecimentos e horários de missas.

Um dos maiores problemas da migração de emissoras AM para FM é justamente a diminuição do sinal das emissoras e o agravamento das zonas de silêncio. A Rádio Itatiaia Ouro Preto, foco da investigação que originou este artigo, terá alcance oito vezes menor após a migração para FM, deixando de atingir os doze distritos e as áreas rurais de Ouro Preto. Esse fato se repete em outras emissoras e, como exposto neste texto, afeta principalmente populações de localidades pequenas e com menores índices de desenvolvimento, além de populações ribeirinhas e pantaneiras.

Em um país com severas áreas de desertos de notícias e zonas de silêncio, a diminuição da abrangência do seu meio de comunicação mais popular e democrático pode representar um agravamento da desinformação e da percepção equivocada sobre a realidade.

\section{Referências}

AGÊNCIA NACIONAL DE TELECOMUNICAÇÕES. A extensão da faixa de FM (eFM) e a migração da faixa de OM: $O$ quê fazer com os canais 5 e 6 da televisão na era digital. Brasília, 2010. Disponível em:

http://www.anatel.gov.br/Portal/verificaDocumentos/documento.asp?numero Publicacao=244137. Acesso em: 28 jun. 2019. ASSOCIAÇÃO BRASILEIRA DE EMISSORAS DE RÁDIO E TELEVISÃO.

Migração AM/FM: conclusão de processo depende de faixa estendida e alteração do regulamento técnico. [s. I.], 29 ago. 2019. Disponível em: https://bit.ly/2qVQ5Tn. Acesso em: 28 out. 2019.

AVRELLA, Bárbara. 0 radiojornalismo local em pequenas emissoras. 2014. 300 fl. Dissertação (Mestrado) - Programa de Pós-Graduação em Jornalismo, Universidade Federal de Santa Catarina, Florianópolis, 2014. BAUMAN, Zygmunt. Identidade: Entrevista a Benedetto Vecchi. Trad. Carlos Alberto Medeiros. Rio de Janeiro: Zahar, 2005. 
BERTOLOTTO, Rodrigo. País sem sintonia: depois de integrar o Brasil por décadas, o rádio vive mudanças que podem provocar o efeito contrário. $\mathrm{UOL}$, 2018. Disponível em: https://tab.uol.com.br/radio/\#pais-sem-sintonia.

Acesso em: 29 jun. 2019.

BOURDIN, Alain. A questão local. Trad. Orlando dos Santos Reis. Rio de Janeiro: DP\&A, 2001.

BRASIL. Decreto no 8.139, de 07 de novembro de 2013. Dispõe sobre as condições para extinção do serviço de radiodifusão sonora em ondas médias de caráter local, sobre a adaptação das outorgas vigentes para execução deste serviço e dá outras providências. Diário Oficial da União, Brasília, 08 nov. 2013. Disponível em: http://www.anatel.gov.br/legislacao/decretos/637decreto-8139. Acesso em: 12 out. 2019.

CANCLINI, Néstor García. Consumidores e cidadãos. 5. ed. Rio de Janeiro: Ed. UFRJ, 2005.

CEBRIÁN HERREROS, Mariano. La radio en la convergência multimedia. Barcelona: Gedisa, 2001.

CURADO, Camila Cristina. Migração de rádios AM para FM: processos de preparação e perspectivas de mudança frente à convergência tecnológica. 2015. 194 f. Monografia (Bacharelado em Comunicação Social) Universidade de Brasília, Brasília, 2015.

DEL BIANCO, Nélia; PRATA, Nair. Rádio, mobilidade e ubiquidade: análise do projeto de inclusão mobile digital da Abert. In: Intercom, Revista

Brasileira de Ciências da Comunicação, São Paulo, v. 41, n. 1, p. 99117, Jan. 2018. Disponível em: https://doi.org/10.1590/1809-5844201815. Acesso em: 19 maio 2020.

FARIAS, Karina Woehl de. ZUCULOTO, Valci Regina Mousquer. Ondas de mudança no rádio: do surgimento à migração do AM para FM. In: Revista Rádio-Leituras, Mariana-MG, v. 08, n. 02, pp. 138-159, jul./dez. 2017. FIDLER, Roger. Mediamorphosis - understanding new media. California: Pine Forge Press, 1997.

GIDDENS, Anthony. Modernidade e Identidade. Rio de Janeiro: Zahar, 2002.

HALL, Stuart. Identidade cultural e diáspora. In: Revista do Patrimônio Histórico e Artístico Nacional. Rio de Janeiro, IPHAN, 1996, p. 68-75. HALL, Stuart. A identidade cultural na pós-modernidade. Trad. Tomaz Tadeu da Silva e Guaracira Lopes Louro. Rio de Janeiro: Editora DP\&A, 2006. HACK, Wellington Felipe; ROSA, Marluza. Desertos de notícias, oásis de desinformação. In: Observatório da Imprensa. [s.l.]: Atlas da Notícia, 08 jan. 2019. Disponível em: http://observatoriodaimprensa.com.br/atlas-danoticia/desertos-de-noticias-oasis-de-desinformacao/. Acesso em: 14 jul. 2019.

INSTITUTO BRASILEIRO DE GEOGRAFIA E ESTATÍSTICA. Pesquisa Nacional por Amostra de Domicílios: síntese de indicadores. Rio de 


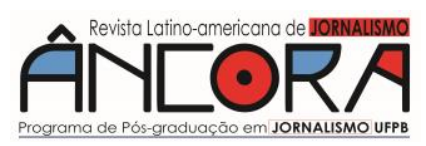

Rafael MEDEIROS

Janeiro: IBGE, 2018.

INSTITUTO PARA O DESENVOLVIMENTO DO JORNALISMO. Atlas da

Notícia: Mapeando o jornalismo local no Brasil. 2019. Disponível em: https://www.atlas.jor.br/. Acesso em: 28 out. 2019.

INSTITUTO PARA O DESENVOLVIMENTO DO JORNALISMO. Atlas da

Notícia versão 3.0: O avanço da revolução digital. 2020. Disponível em: https://bit.ly/3aj30Aw. Acesso em: 23 mar. 2020.

JOBIM, Ruy. Um papo sobre o rádio carioca, Prêmio Rádio Rio e também a migração. In: Tudo Rádio. Disponível em:

https://tudoradio.com/entrevistas/ver/150-ruy-jobim. Acesso em: 11 abr.

2019.

KANTAR IBOPE MEDIA. Book de Rádio. 2018a. Disponível em:

https://www.kantaribopemedia.com/wp-content/uploads/2018/09/Book-deR\%C3\%A1dio-2018.pdf. Acesso em: 02 jan. 2020.

KANTAR IBOPE MEDIA. Audiência de Rádio Grande Belo Horizonte

Setembro a Novembro/2016. 2018b. Disponível em

https://www.kantaribopemedia.com/grande-belo-horizonte-setembro-anovembro-2016/. Acesso em: 04 abr. 2019.

KISCHINHEVSKY, Marcelo. Rádio e mídias sociais: mediações e interações radiofônicas em plataformas digitais de comunicação. Rio de Janeiro: Mauad X, 2016.

LOPEZ, Debora Cristina. La radio en narratives immersives: le contenu journalistique et l'audience. Trad. Debora Cristina Lopez. In: POULAIN, Sebastien (org.). La radio du futur: du téléchromophotophonotétroscope aux postradiomorphoses, Cahiers d'histoire de la radiodiffusion, $\mathrm{n}^{\circ} 132$, avril-juin, 2017.

LOPEZ, Debora Cristina et. al. Reposicionamento do radiojornalismo frente aos novos desafios da migração do AM para o FM: análise de caso de quatro emissoras tradicionais. In: Anais... $16^{\circ}$ Encontro Nacional de Pesquisadores em Jornalismo. São Paulo: SBPJor, 2018. Disponível em:

http://sbpjor.org.br/congresso/index.php/sbpjor/sbpjor2018/paper/viewFile/1 325/768. Acesso em: 11 mar. 2020.

MACEDO, Danilo. Dilma assina decreto autorizando migração de rádios AM para FM. [s.I]: Tecnologia, 2013. Disponível em:

http://www.ebc.com.br/noticias/politica/2013/11/dilma-assina-decretoautorizando-migracao-de-radios-am-para-fm>. Acesso em: 21 jun. 2018. MARTÍN-BARBERO, Jesús. Globalização comunicacional e transformação cultural. In: MORAES, Denis de (Org.). Por uma outra comunicação: mídia, mundialização cultural e poder. Rio de Janeiro: Record, 2003. MASSARO, Carlos. Rádio amplia esforços no cenário internacional para seguir relevante entre as montadoras de automóveis. In: Panorama Tudo Rádio, 28 maio 2018. Disponível em: https://tudoradio.com/noticias/ver/19645panorama-radio-amplia-esforcos-no-cenario-internacional-para-seguirrelevante-entre-as-montadoras-de-automoveis. Acesso em: 01 jul. 2019. MEDEIROS, Rafael. 0 rádio e a cidade patrimônio: experiências de 
escuta, localismo e migração nos discursos de ouvintes Ouro-Pretanos. 2019. 276 f. Dissertação (Mestrado em Comunicação) - Universidade Federal de Ouro Preto, Mariana, 2019. Disponível em:

<https://www.repositorio.ufop.br/handle/123456789/11310>. Acesso em: 19 maio 2020.

MÜLLER, Felipe de Matos; SOUZA, Márcio Vieira de. Fake News: Um problema midiático multifacetado. In: International Congress of

Knowledge and Innovation - Ciki, [S.I.], v. 1, n. 1, set. 2018. Disponível em: http://proceeding.ciki.ufsc.br/index.php/ciki/article/view/511. Acesso em: 11 maio 2020.

OBSERVATÓRIO DA IMPRENSA. 30\% dos municípios brasileiros correm o risco de virar desertos de notícias. In: Atlas da Notícia 2.0: Todas as mídias no novo levantamento. Disponível em:

http://observatoriodaimprensa.com.br/atlas-da-noticia-2-0/30-dosmunicipios-brasileiros-correm-o-risco-de-virar-desertos-de-noticias/. Acesso em: 12 maio 2020.

ORTIZ, Renato. Um outro território: ensaios sobre a mundialização. São Paulo: Olho D’água, 1999.

PERUZZO, Cicilia. Mídia regional e local: aspectos conceituais e tendências. Comunicação \& Sociedade. São Bernardo do Campo: Póscom-Umesp, a. 26, n. 43, 2005.

PRATA, Nair. Webradio: novos gêneros, novas formas de interação. Tese (Doutorado) - Programa de Pós-Graduação em Estudos Linguísticos da Faculdade de Minas Gerais, Belo Horizonte, 2008.

RADDATZ, Vera Lucia. Rádio AM "avisa": uma expressão da cultura local. In: KLÖCKNER, Luciano; PRATA, Nair (orgs.). Mídia sonora em 4 dimensões: $1^{\mathrm{a}}$ ouvintes e falantes, $2^{\mathrm{a}}$ memória política, $3^{\mathrm{a}}$ programas de rádio, $4^{\mathrm{a}}$ tecnologia e futuro. Porto Alegre: EdiPUCRS, 2011.

RONSINI, Veneza Mayora. Mercadores de Sentido: consumo de mídia em identidades juvenis. Porto Alegre: Sulina, 2007.

ZUCULOTO, Valci Regina Mousquer et. al. Transformações contemporâneas do rádio em Santa Catarina: perspectivas de um novo dial frente às mudanças na migração do AM para o FM. In: Anais do $41^{\circ}$ Congresso

Brasileiro de Ciências da Comunicação - Intercom, Joinville, 2018. São Paulo: Intercom, 2018. Disponível em:

http://portalintercom.org.br/anais/nacional2018. Acesso em: 11 fev. 2020.

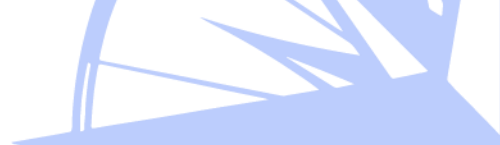

